\title{
JOURNAL OF PHILOSOPHICAL STUDIES
}

have not, we set those influences to work on the children of succeeding generations, with the expectation that they will have their effect in the actions which they will choose to do."

"We do, in fact, dimly recognize that, while we cannot trace the effect of all the vast complex of causes that determine character, we can here and there trace the effects of some of them. It is for that reason that we try to set on foot those agencies which will influence character, and therefore influence the choice of actions, in a way that will benefit the individual and the society."

"Since, however, emphasis is laid on the principle of causation, the doctrine, if it were generally held, should lead, not to a fatalistic apathy, but to a more intense activity, designed to ensure that the causes which will mould the future shall be as beneficent as they can be made."

I suggest that such language is pointless and confusing, unless we have the power not "to set on foot those agencies which will influence character," etc. The determinist" can speak legitimately, of course, of agencies influencing character, but he is guilty of an informal contradiction if he adds the conception of "ought" to his formula, which the author does in the quotations given. The sense of "oughtness" may be regarded as one of the factors which determines character, but the "oughtness" itself must be for the determinist an illusion having no ontological significance.

An idea of great importance in man's higher experience is expressed by the doctrine of free will; but formal thought, perhaps by its very nature, seems to favour determinism. The object of this letter is to contend that no light is thrown on this ancient problem by the use of the word "relativity"- a word clearly borrowed in this case from physics, which is a study of events on a lower level than that of mind.

WALLINGTON,

ERnest F. Champness.

July, 1929.

To THE EDITOR OF THE Journal of Philosophical Studies.

\section{SCIENCE AND REALITY.}

Dear Sir,

Volume No. 37 in Benn's Library is an interesting Essay on Science and Reality by Professor R. A. Sampson, Astronomer Royal for Scotland.

On page to he divides the Sciences with which he has to deal into three distinguishable regions according as these concern Thought, Observation, and Life, and he takes as illustrations of their character and differences the sciences of Geometry, Astronomy, and Medicine.

We suggest that the place which is thus assigned to Geometry is incorrect. Geometry is not in any special sense the Science of Thought. All science is the constant product of observation and thought, but Thought is not the object of geometrical, any more than of astronomical, reasoning.

There is a Science of the Laws of Thought-we call it Logic or Epistemology. Its sphere is well defined, and does not include any properties of space. The metaphysician and psychologist are therefore within their rights in challenging the view that Thought is the object of geometrical reasoning. What then is that object? Geometry, we suggest, is the Science of the forms of the free mobility of our bodily organism amidst its environment.

The question is important. If the view we have expressed is sound, the propositions of Euclidean Geometry are for us necessary, and a priori. This does not prevent the human mind from formulating a Geometry which is independent of the bonds of the Euclidean system. That has been done; but such Geometry does not apply to our physical experience.

Professor Sampson, on page II, speaking of Euclidean Geometry, tells us that "its arguments are still regarded as valid, but they are now seen to be not inevitably so." 


\section{COR RES P ON DENCE}

This rather indefinite statement is made clear when we recognize two degrees of apriority:-

(1) The apriority of Pure Thought.

(2) The apriority of the forms of our free activity.

The proposition which we have challenged expresses, we believe, the general view of scientists to-day. In view of recent discussions it is important to know whether it is accepted by psychologists. In short, is Geometry, as recent Science suggests, a self-contained system of enumerated postulates which can be discarded at pleasure, or is it a description of the characters of our organic activity, and therefore for us necessary and apodeictic?

$$
\text { Yours faithfully, }
$$

Alex. Philip.

The Mary Acre,

BRECHIN.

September, 1929.

A Posrhumous portrait of the late F. H. Bradley, O.M., Fellow of Merton College, has been painted by Mr. R. G. Eves, and can be seen at the College.

Subscriptions towards the cost of the portrait will be received at Barclays Bank Ltd. (The Old Bank), High Street, Oxford. Subscribers of one guinea and upwards will receive a photogravure copy. Cheques should be paid to the "Bradley Portrait Fund" and crossed "Barclays Bank." A sum of about $£ 250$ is required.

Any surplus will be applied to the expenses of the Bradley Library, which has been founded out of a bequest made by Mr. Bradley to the College.

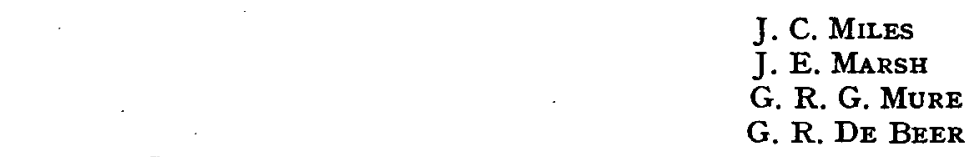

Merton College,

July 1929. 